\title{
School and Qualitative Educational Services - as a Key for a Stable Social Development
}

\author{
Prof. Assoc. Dr. Xhevdet Zekaj \\ Lecturer at "Aleksander Xhuvani" University \\ xhzeka@yahoo.com
}

\section{Doi:10.5901/ajis.2015.v4n1s1p165}

\begin{abstract}
In this article it will be treated and analyzed the problem of narcotic drugs in Albanian society during the years of transition from the point of view of the general forming, through education and social contribution. School has a primer role, especially in this moments, when Albania is about to be integrated in European Union. We tend to educate a formed society with future stable progress to be integrated with dignity in the European society. It should be stressed that we still have a group of student who tend to have unstable attitudes, which we see as an opportunity for a future society with stable attitudes through education in our institutions. At this point, school as a specialized educational and formed institution, should take the responsibilities and insure that a maximum number of students will not be part of the victims, abusing with narcotic drugs. This requires the sensible of the entire society for the long and difficult battle against drug abusing. Some of the most problematic issues that threaten our society are: exposure to alcohol, smoking, and narcotic drug abusing; modern attitude through clothing, behavior group part; tendency or a dissolution to sexual life; schools drop out without having the right educational level; low level of education brings social distortion. Facing different type of pressures in their life, most of the case youth do not know which place they belong to or are part of. Some of the cases where students feel to have failed are those areas they tend to be part of, but in relation to their peers they feel like being less superior than other ones. As a conclusion, we suggest that school should aim and offer educational services that tend to be effective and successful for students education with a qualitative future citizens in a democratic society. Data collection and analysis will take place on the development of the material.
\end{abstract}

Keywords: abuse, narcotic drugs, education, educational institutions, citizens, democratic, society

\section{Introduction}

Republic of Albania is one of the Western Balkan countries in South-Eastern Europe, which borders Italy across the Adriatic Sea and Ionian Sea on the west, Greece on the south and southeast, Republic of Macedonia on the east, Kosovo on the northeast and north and Montenegro on the north and northwest.

The population of Albania, as registered officially in the Population and Dwellings Census of 2001 amounted to 3 069275 inhabitants (INSTAT, 2002). In 2008, Albania's population was calculated to be 3170048 inhabitants, with a density of 110 inhabitants per square kilometer. Compared to 2001, Albania's population has increased with approximately 106748 persons. Average life expectancy at the time of birth for the $2005-2008$ period was 72,1 years for males and 78,6 years for females. Life expectancy in urban areas is higher than in rural areas. More than $98 \%$ of the population is ethnic Albanians, with the minorities including small groups of Greeks, Macedonians, Vlachs, Roma, Bulgarians and Serbians. Religion was prohibited during the communist period; Albanians in their majority do not practice any religion, but nominally the population belongs to three main religions: Muslims (present over the whole country), Catholic C hristians (present mostly on the north) and Orthodox Christians (concentrated mostly on the south). The official language is Albanian.

The general number of adults (15-64 year old) who have tried various illegal drugs is estimated to have been around 5000 (life prevalence 0,2\%) in 1995 and 20000 (life prevalence 1,0\%) in 1998, whereas current figures fluctuate between 40000 and 60000 (life prevalence between 2,0\% and 2,8\%), which shows a considerable increase since 1995. A progressive analysis of service users and two studies on risky behaviors among high school youths, indicate a rise of prevalence, both in terms of experimenting with drugs and abusing with them.

The collection of information for this report (document) was made possible through the revision of all published or non-published materials, and the existing databases. Another important source were persons with knowledge in depth on the system and experienced in the field (key informants). 


\section{Participants}

The sample included 30 high school students of an urban area in Albania ( Elbasan) on which $57 \%$ were men $(n=17)$ and $43 \%$ were women $(n=13)$. Age $16-17$ years old.

\subsection{Aim of the study}

I. Evaluation of knowledge that teenagers have about drugs, smoking and alcohol usages' damages

II. Evaluation of diffusion of drugs, smoking and alcohol phenomenon

\subsection{Objectives}

I. Measure the diffusion of information and number of teenagers' smokers

II. Measure the diffusion of information and number of teenagers' drug users

III. Measure the diffusion of information and number of teenagers' alcohol users

\subsection{Hypothesis}

I. There is a considerable information at schools' environments about damages caused by alcohol, drugs' usage and smoking

II. Number of smokers, drug usage and alcohol is very high among teenagers

\section{Methodology}

Collection of information for this document became possible by the revision of all published or unpublished materials, and the existing database. Another important source were also persons who offered to be part of our study, in our case high school students.

Used methodology in this study in order to have soma data about the level of the usage and consume of smoke, alcohol and narcotic substances is a questionnaire with different questions to teenagers, high school students. It took place to students of XI grade, age 16-17 years old in Elbasan city. There were 30 students that were part of the study case. The selection was randomly chosen but purposely. In 30 students, $57 \%$ were men $(n=17)$ and $43 \%$ were women $(n=13)$.

Questionnaire includes questions about, smoke, drugs and alcohol. Considering the aim of this study we tend to find out some data about the level of smokers, alcohol and drug usage by also considering the fact that teenagers tend not to tell the truth in person, we used this anonymous way of collecting the data.

\subsection{Policies and Legal Framework on the case study in Albania}

In the Republic of Albania, before the 1990s there were no problems related to drug abuse cause of the isolation of the country and the existing policies at that period. Problems related started after the transition period, after the '90s especially during 1994-1995.

In the meantime, alcohol in Albania has been traditionally considered a lawful drug and, despite spontaneous efforts to keep it under control, no legal framework or coordinated policies have been instituted until the middle of the first decade of $21^{\text {st }}$ century.

Catalysts for the development of strategies and legislation during these years have been:

$>$ the consolidation of state and institutions;

$>$ the process of integration in international organizations and the stabilization-association process in EU; and

$>$ the growing drug and alcohol problems

Policies to be undertaken on the case:

$>$ Preventive and reduction policies for alcohol-related harm;

$>$ Political commitment and government's role;

$>$ Health impact of alcohol;

$>$ Health treatment of disorders related to alcohol abuse; 
$>$ Actions at a national and local level;

$>$ Evaluation of the drug situation through a combination of quantitative and qualitative techniques;

$>$ Establishment of the epidemiological surveillance network;

$>$ Creation of a database and resource centers

\subsection{Preventive interventions nationally implemented}

Several associations have offered preventive interventions together with harm reduction programs by targeting high-risk groups, such as truant pupils, those who fail in their grades, etc. The employed methods include lectures, group discussions, and presentations of conclusions of exercises conducted by the group.

Several sporadic activities have been experimented by health specialists in cooperation with police specialists during night hours for curbing down alcohol use by youths (2009).

Prevention campaigns in high schools have been on the increase, even though on an annual average, only a small number of schools are involved in informing and awareness campaigns in the country (indicator B of SAIMS -1-20\%).

In some large national school-based campaigns, the emphasis was put on a healthy lifestyle and included drugs and alcohol, such as in the case of "Live healthily" campaign, supported by UNICEF and UNFPA, or in the case of the "Youths without smoking and alcohol" campaign, organized by the Ministry of Health in cooperation with the Ministry of Education and Science. Coverage of schools in these campaigns has been large (indicator C of SAIMS - 21-50\%).

In an analysis to the coverage with trainings and other information, awareness and counseling activities in 2009 , it may be assessed that between 2000 and 2500 youths from high schools in the country were reached, which represents around $1 \%$ of the total number of pupils and students in the country's high schools and universities.

The methods used include lectures, group discussions, interactive communication and, in some cases, the use of life abilities and peer leaders.

There is no organized system in place for interventions into schools. Every government or non-government agency follows up individual projects, and there is not in place, as a consequence, a systematic evaluation of the interventions.

There have been also campaigns that aimed at increasing the amount of information and awareness to teachers and health personnel on drug and alcohol problems.

Since 2006, the Ministry of Education and Science has assigned psychologist workers in high schools and 9-year cycle schools; their task is, among other things, to detect early drug and alcohol-related problems, and provide appropriate assistance. These professionals are operating in practice only in schools in urban areas and cover approximately about 3 schools for each employee.

Even though there have been projects supported by foreign donors for increasing the capacities of these professionals through training, there is no detailed information on these trainings.

Since four years now (from 2010 onwards), a new program has been introduced in the high schools of Albania as a part of the mandatory curriculum, named "living and career abilities". There is a special chapter in this program on drugs and alcohol. Among other things, the program includes practical abilities, such as stress management, social skills, emotional communication, abilities to cope with change, etc. The program is taught by biology teachers and psychologists in schools.

In 9-year cycle schools, as well, basic knowledge is given on substance abuse in the subjects of biology and health education.

\section{Study Case}

The data collected from the questionnaires were elaborated in the Excel Program. Building of tables with the data from the study helped us in the construction of conclusion and recommendations. Presentation of data collected from the study has been divided in some important parts: information over the consequences of smoke, drug and alcohol usage; consume by teenagers and the way they provide them; usage in society and their families.

In relation to the information gathered from students of high school over the consequences of smoking, $90 \%(27)$ of them admitted they are aware of the damages of smoking, 7\% (2) said they did not have information and 3\% (1) said they had little information about this.

About the consequences of drug usage $73 \%$ (22) admitted they were aware of them and only $27 \%$ (8) said they did not have information about this. According to the negative effects of alcohol usage $90 \%$ (27) of them admitted to have information, 3\% (1) did not and 7\% ( 2) said they had little information about alcohol consuming effects. 
$>$ Smoking, alcohol and drug usage by students and the ways of providing them.

About $87 \%$ (26) of students admitted they have smoked in their life and $47 \%$ that they have smoked more than five times, 1-5 times was the number of times that $40 \%$ of them have smoked. There was a $10 \%$ of them that confessed they never smoked in their life. About $47 \%$ of students admitted that start smoking by their initiative without being influenced from someone else, and other $40 \%$ said it was cause of their social group pressure. In the case of drug usage, $40 \%$ of admitted that they have consumed narcotic substances, $23 \%$ of them said they have tried it 1 to 5 times and 7\% more than 5 times. Most of the students, almost $60 \%$ said they never tried narcotic drugs. A $23 \%$ of students said that drug was offered by their social group and only $10 \%$ of them said it was their free will.

About $93 \%$ of students admitted they have consumed alcohol, $53 \%$ of them have tried it 1 to 5 times and $37 \%$ more than 5 times. $50 \%$ of them said it was their initiative to consume alcohol while $43 \%$ said it was offered by their social group. Only $7 \%$ of students said they never consumed alcohol in their life.

$>$ Usage in society and families.

Smoking in their social group was $37 \%$ which happened always, and $63 \%$ said that it was something that happened most of the time in their close social group. About $57 \%$ of students.

A very high percentage was in the fact that $37 \%$ admitted that their social group was that of narcotic substances and it was used very often, $7 \%$ said it happened during all the time and $56 \%$ said it never happened.

About $73 \%$ admitted that alcohol was used very often in their social group and $20 \%$ said that their close friends always drink alcohol. Even the usage of alcohol in their families is in high percentage, about $47 \%$ admitted that it happened very often, $23 \%$ said it happened always and $30 \%$ said it was never consumed in their families.

\subsection{Data Analyses}

$>$ Students of the XI grade in high school do have information about the negative effects of smoking, drug usage and drinking alcohol. It was about $90 \%$ of them

$>$ Generally, students admitted they have at least smoked once in their life, drunk alcohol and tried narcotic substances. The highest percentages were in the smoking case, about $87 \%$, alcohol, $93 \%$ alcohol and $40 \%$ of those who used narcotic substances.

> About $47 \%$ of them admitted to have start smoking by their own initiative as well the alcohol with $50 \%$ of them. Social group have more influence than curiosity with a $23 \%$ of them when we deal with narcotic substances.

> The major part of students said smoking is about $63 \%$ in their social group, alcohol $73 \%$ and $37 \%$ of narcotic substances.

$>$ About $57 \%$ of them admitted that smoking is part of their family life and alcohol about $70 \%$.

\section{Conclusions}

$>$ The major part of students of $\mathrm{XI}$ grade have information over the negative effects of smoking, alcohol and narcotic substances

$>$ There is a high number of 16-17 years old students that admit to "taste" smoking, alcohol and narcotic substances

$>$ In the case of smoking and drinking alcohol the major part admit to be of free will while in the case of narcotic substances it a social influence

$>$ In the major part of students results that their social group consume very often alcohol, narcotic substances and smoking

$>$ In the study case both hypothesis were proved to be true

\section{Recommendations}

$>$ Increase of sensibilization over the damages caused by smoking, alcohol and drugs

$>$ Enforcement of tobacco shops over the sale of cigarettes to people under 18 years old

$>$ Increase of police forces in preventing drug sale 
Table of Questionnaires' Results

\begin{tabular}{|c|c|c|c|c|c|c|c|c|c|c|c|c|c|c|c|c|c|}
\hline \multirow{2}{*}{$\begin{array}{c}\text { No. of } \\
\text { questionnaire }\end{array}$} & \multicolumn{3}{|c|}{ Gender } & \multicolumn{2}{|c|}{$\begin{array}{l}\text { Information over } \\
\text { alcohol damages }\end{array}$} & \multicolumn{2}{|c|}{$\begin{array}{c}\text { Ever } \\
\text { drunk } \\
\text { alcohol? }\end{array}$} & \multicolumn{2}{|c|}{$\begin{array}{l}\text { If Yes, how } \\
\text { many times? }\end{array}$} & \multicolumn{2}{|c|}{ Who offered to you? } & \multicolumn{3}{|c|}{$\begin{array}{l}\text { Is alcohol consumed } \\
\text { in your social group? }\end{array}$} & \multicolumn{3}{|c|}{$\begin{array}{l}\text { What about in your } \\
\text { family? }\end{array}$} \\
\hline & $\mathbf{M}$ & $F$ & Yes & No & A litle & Yes & No & \begin{tabular}{|c|}
$1-5$ \\
Times
\end{tabular} & More & Self-initiative & Friends & Always & Often & $\begin{array}{c}\text { Not at } \\
\text { all }\end{array}$ & Always & Often & n Not at all \\
\hline 1 & & 1 & 1 & & & 1 & & 1 & & 1 & & 1 & & & 1 & & \\
\hline 2 & 1 & & & & 1 & 1 & & 1 & & & 1 & & 1 & & & & 1 \\
\hline 3 & 1 & & 1 & & & 1 & & 1 & & 1 & & 1 & & & 1 & & \\
\hline 4 & 1 & & 1 & & & 1 & & & 1 & & 1 & & 1 & & & & 1 \\
\hline 5 & & 1 & 1 & & & 1 & & 1 & & & 1 & & 1 & & & & 1 \\
\hline 6 & 1 & & 1 & & & 1 & & 1 & & 1 & & & 1 & & & 1 & \\
\hline 7 & 1 & & 1 & & & 1 & & & 1 & 1 & & & 1 & & 1 & & \\
\hline 8 & & 1 & 1 & & & 1 & & & 1 & 1 & & & 1 & & & 1 & \\
\hline 9 & & 1 & 1 & & & 1 & & 1 & & & 1 & & 1 & & 1 & & \\
\hline 10 & 1 & & & 1 & & & 1 & & & & & & & & & 1 & \\
\hline 11 & 1 & & 1 & & & 1 & & 1 & & 1 & & & 1 & & & 1 & \\
\hline 12 & & 1 & 1 & & & 1 & & & & 1 & & 1 & & & 1 & & \\
\hline 13 & & 1 & 1 & & & 1 & & 1 & & 1 & & & 1 & & & 1 & \\
\hline 14 & 1 & & 1 & & & 1 & & & 1 & 1 & & & 1 & & & 1 & \\
\hline 15 & 1 & & 1 & & & 1 & & & 1 & 1 & & & 1 & & & & 1 \\
\hline 16 & 1 & & 1 & & & 1 & & & 1 & & 1 & & 1 & & & 1 & \\
\hline 17 & 1 & & 1 & & & 1 & & 1 & & 1 & & & 1 & & & 1 & \\
\hline 18 & 1 & & 1 & & & 1 & & 1 & & & 1 & 1 & & & 1 & & \\
\hline 19 & & 1 & 1 & & & 1 & & 1 & & 1 & & & 1 & & & & 1 \\
\hline 20 & 1 & & 1 & & & 1 & & 1 & & & 1 & & 1 & & & 1 & \\
\hline 21 & 1 & & 1 & & & 1 & & & 1 & & 1 & 1 & & & & & 1 \\
\hline 22 & & 1 & 1 & & & & 1 & & & & & & & 1 & & 1 & \\
\hline 23 & & 1 & & & 1 & 1 & & & 1 & 1 & & & 1 & & & 1 & \\
\hline 24 & 1 & & 1 & & & 1 & & 1 & & & 1 & & 1 & & & & 1 \\
\hline 25 & & 1 & 1 & & & 1 & & 1 & & & 1 & & 1 & & & & 1 \\
\hline 26 & & 1 & 1 & & & 1 & & & 1 & & 1 & & 1 & & & & 1 \\
\hline 27 & 1 & & 1 & & & 1 & & 1 & & & 1 & & 1 & & 1 & & \\
\hline 28 & & \begin{tabular}{|l|}
1 \\
\end{tabular} & 1 & & & 1 & & 1 & & 1 & & & 1 & & & 1 & \\
\hline 29 & 1 & & 1 & & & 1 & & & 1 & 1 & & 1 & & & & 1 & \\
\hline 30 & & 1 & 1 & & & 1 & & & 1 & & 1 & & 1 & & & 1 & \\
\hline & 17 & 13 & 27 & 1 & 2 & 28 & 2 & 16 & 11 & 15 & 13 & 6 & 22 & 1 & 7 & 14 & 9 \\
\hline
\end{tabular}

\section{References}

|1| Council of Europe (1996), 'Seminar on Information Systems and Applied Epidemiology of Drug Misuse for Albanian Experts (Tirana, Hotel Rogner "Europapark" 18-20 December, 1995)', Pompidou Group, 5 January, P-PG (96) 1.

|2| Albania: 'Demographic and Health Survey in Albania (DHS) 2009'. Prepared by the Mixed Working Group of the Institute of Public Health (IPH) and the Institute of Statistics (INSTAT) of Albania, under the technical supervision of external experts. Published by the UNFPA-UNICEF both in English and Albanian, 2010.

|3| Council of Europe (1996), 'Seminar on Information Systems and Applied Epidemiology of Drug Misuse for Albanian Experts (Tirana, Hotel Rogner "Europapark" 18-20 December, 1995)', Pompidou Group, 5 January, P-PG (96) 1. Institute of Public Health, USAID, FHI, and ISOP (2006), 'Albania Behavioral and Biological Surveillance Study Report', Family Health International publication, Tirana.

|4| Kakarriqi, E. (1999), 'Albania National Report on Primary Drug Prevention within the Community', PHARE Programme TA to DDR (Technical Assistance to Drug Demand Reduction), October.

|5| Institute of Public Health (2009), 'Youth Risky Behaviour Survey, second round, 2009', Institute of Public Health Report, Tirana, September 2009

|6| Albania: 'Country Overview 2011 (data till 2010)'. Prepared by the Working Group of Albania: Ylli A, Sulaj Z., Bino S, Bani S. Selfollari S. (IPA3-EMCDDA Project 2010-2011 on the Western Balkans Countries). Edited by Kakarriqi E. (National Correspondent of Albania of the IPA3-EMCDDA Project 2010-2011 on the Western Balkans Countries). Published both in English and Albanian (in the EMCDDA website) by the EMCDDA, 2011. 